\title{
Death Attitudes and Perception about the Death of the Vietnamese Elderly
}

\author{
Hoang Moc Lan, Trinh Thi Linh*, Ngo Mai Trang \\ Faculty of Psychology, University of Social Sciences and Humanities, Vietnam National University, Hanoi, Vietnam \\ Email: lanhoangmoc@yahoo.com, ^anhlinh_huong@yahoo.com,trang_maingo@yahoo.com
}

How to cite this paper: Lan, H.M., Linh, T.T. and Trang, N.M. (2017) Death Attitudes and Perception about the Death of the Vietnamese Elderly. Open Journal of Social Sciences, 5, 300-317. https://doi.org/10.4236/jss.2017.510026

Received: October 3, 2017

Accepted: October 28, 2017

Published: October 31, 2017

Copyright @ 2017 by authors and Scientific Research Publishing Inc. This work is licensed under the Creative Commons Attribution International License (CC BY 4.0).

http://creativecommons.org/licenses/by/4.0/

\section{cc) (i) Open Access}

\begin{abstract}
This study aims to examine the death attitudes and perception about the death of the elderly in Vietnam in the current period. Using the scale based on the research work of Wong and his colleagues (1994) and concepts of Buddhism, the study was performed on 959 elderly people in three areas: The Nord, the Centre and the South of the country. Results of data analysis show that only a part of the studied believe in afterlife. They tend to believe that their death is caused by pain, sadness and missing dear people instead of the supernatural that force them to die. Concerning death attitudes, we note that the majority of the studied will make actions expressing their willingness to accept death. Age, education, gender and life arrangement affect death perception as well as death attitudes in which we also note the difference by self-reported health and satisfaction of material life.
\end{abstract}

\section{Keywords}

Death Attitudes, Belief in Afterlife, Fair of Death, Causes of Death, Vietnamese Elderly

\section{Introduction}

Life and death are inter-related and are often seen as two sides of the same coin. Unfortunately, many people see death as a taboo topic and may therefore be reluctant to discuss death (Feifel, 1959, cited according to [1]). Nowadays, Bryant and Peck [2] emphasize that with the longevity revolution, for the first time in history, death has become a province of the old. During the $20^{\text {th }}$ century, life expectancy increased by two thirds in the developed world. Increasingly its members die upon the conclusion of full, completed lives; in the United States, nearly 8 in 10 deaths occur among those 65 and older. Although this would seem to be the cause for collective celebration, instead old age has become a social problem. 
When mentioning the old age, it is impossible not to mention the elderly's attitude toward death. In reseaches, the old age and death always come together.

In reality, people have to face the dilemas representingthe death. On one hand man want to maintain life, on the other hand they are aware that death is a certain thing. Accordingly, several attitudes form to allow man to be free from the worry of the limitation of life. Tomer [3] reviews several philosophical approaches towards death. Each of these philosophies has implications for the meaning of life. For example, Martin Heidegger's position is that since death is a threat of non-existence, it provides the precondition for fuller understanding of life, thereby freeing us from anxiety. For Sartre, death reduces one's being to nothingness; therefore, to reflect on death is to realize the meaninglessness of existence. In general, there are different perception of death deriving from different angles of view which are plentiful and diversified in Asian countries like Vietnam where worshiping ancestors is considered to be a "religion". Accordingly, everyone, Buddhist or Catholic or Protestant, worships their ancestors at home. Thus they believe that death is to "unite with their ancestors". Besides, Buddhism and Catholicism play a considerable part in people's view of the existence of the second life after death. We can say that the traditional religion in Vietnam is Buddhism. Under this belief system, it was thought that individuals are reincarnated many times to purify themselves and attain wisdom. Reincarnation is affected by one's conduct in life. If one sins, one can be reborn as an insect or animal. If one performs many good deeds, one would be reincarnated as a person, and eventually reach Nirvana, when rebirth ceases and paradise is achieved (Gyatso, 2003, cited according to [4]). In the view of Catholicism (Christian), death is the destruction of the body, but the soul is not dead. In other words, according to Christian death doesn't mean the end but a new eternal life. So, depending on their virtue and good deeds during lifetime, their soul would be judged by God to proceed to Heaven, Purgatory or Hell. These views maybe unscientific for the vast of epistemologists but this fact indicates that it influences people's attitudes and belief when preparing to face death.

In other words, we can say that death attitudes and perceptions about the death blend in culture and religion. Depending on the culture as well as on the personal believes and the explanation of death, one can perceive such event as it causes fear, frightening and they try to repel it as much as possible. For many other cultures and religions, on the contrary, death is not perceived as an end but a shift from one state to another, a step into a new and better life, transforming into the highest level of existence. For some, death can be a way of realizing the desire of escaping from long-term misery that sometimes brings along sickness and agedness. In other cases, for instance, for those who commit suicide, death becomes the last and desperate mean to escape from the reality full of misery and misfortune. There are plenty of meanings of death thus different attitudes and people believe toward death.

Wong, Reker and Gesser (1994, cited according to [3]) provide a broader conceptual framework for death attitudes, which include fear of death, neutral 
acceptance and approach acceptance. Fear of death can be considered the most powerful and universal death attitude. In general, people are afraid of death for many reasons. According to Tomer [3], some of the common reasons are fear of the pain of dying, fear of separation, fair of the unknown, and fear of divine judgment. Another type of existence fear is that death will come before one has lived a meaningful life. Butler (1963) even suggests that people are more afraid of a meaningless existence than of death. The effects of fear of death are complex and pervasive. At one extreme, individuals may have the exhilarating feelings of being free from the iron grip of fear of death. At the other extreme, individuals may live very cautiously in a protected "bubble"-they are extremely safety conscious and don't want to try anything.

Neutral acceptance refers to coming to terms with the inevitable reality of personal mortality, no matter how uncomfortable one may feel. All living things must die. Death is just a natural cycle of life. One has to accept this fact at the cognitive level, and then gradually adjust to it at the affective level. Neutral acceptance can have different effects on how one lives. Some may feel that since life is short, they should indulge in hedonistic behavior-"let's eat and be merry, because tomorrow we die". A more positive type of neutral acceptance is related to self-actualization. Given the brevity of life, some people may want to make good use of their time and accomplish something worthwhile and significant. Both Kaufmann (1976) and Goodman (1981, cited according to [3]) have also proposed the idea of conquering the fear of death through self-actualization; being able to accomplish meaningful life goals leads to death acceptance.

However, in Vietnam, no research has specialized in these topics or there are only some studies of psychics about life after death and near death experience of those who have "risen from the dead". Thus what is the Vietnamese elderly's conception of death? Do they really believe that there is life after death? In their opinion, what are the reasons of the elderly's death? How do they act to prepare for the death "coming closer" at their age? How do the demographic factors such as age, gender, educational level... influence the attitudes and belief of the Vietnamese elderly toward death? We believe that an epidemiology research aiming to answer the questions above is necessary and embeds deep practical and theoretic meaning for the researching fields related to the elderly in Vietnam in the current period. In the light of above literature reviews, the current study aim to examine: 1) the perception of Vietnamese elderly about the death; 2) their death attitudes; and also 3) the relation between self-reported health, self-reported on satisfaction of material life and death attitudes of this population.

\section{Method}

\subsection{Participants}

The population of this study consists of 959 elderly people (from 60 to 80 years-old) who are now living in 6 provinces/cities of Viet Nam (Ha Noi, Thai Binh, Nghe An, Khanh Hoa, Ho Chi Minh, Kien Giang). These provinces/cities 
represent three regions within Vietnam (Northern, Central and Southern). In each region, we chose 1 big city and 1 nearby province where lived plenty of elderly people. Specifically, we selected Hanoi city and Thai Binh province in the North, Khanh Hoa city and Nghe An province in the Center, Ho Chi Minh city and Kien Giang province in the South. In each province, we selected 150 elderly people, and 200 elderly people in the each most populated cities Hanoi and Ho Chi Minh. The obtained data don't show any statistically significant differences for the age $(p>0.05)$. The demographic characteristics of the sample are represented in Table 1.

\subsection{Materials}

Based on the research work of Wong, Reker and Gesser and concepts of Buddhism-one of the principal religions in Vietnam, we have developed a questionnaire consisting of two parts: 1) demographic questionnaire, 2) measuring the

Table 1. Background information of inquiry participants.

\begin{tabular}{|c|c|c|c|}
\hline $\begin{array}{l}\text { Demographic } \\
\text { characteristics }\end{array}$ & Criterions & $\mathrm{N}$ & $\%$ \\
\hline \multirow{5}{*}{ Age } & $60-64$ & 364 & 38.0 \\
\hline & $65-75$ & 455 & 47.4 \\
\hline & $>75$ & 140 & 14.6 \\
\hline & Live alone & 39 & 4.1 \\
\hline & Live with spouses & 342 & 36.0 \\
\hline \multirow[t]{4}{*}{ Living arrangement } & Live with wife/husband and children & 442 & 46.5 \\
\hline & Live with children & 114 & 12.0 \\
\hline & Live with relatives & 14 & 1.5 \\
\hline & Married & 818 & 85.3 \\
\hline \multirow{3}{*}{ Marital status } & Divorced & 16 & 1.7 \\
\hline & Separated & 1 & 0.1 \\
\hline & Widowed & 124 & 12.9 \\
\hline \multirow{2}{*}{ Sex } & Male & 667 & 69.6 \\
\hline & Female & 292 & 30.4 \\
\hline \multirow{5}{*}{$\begin{array}{l}\text { Educational } \\
\text { background }\end{array}$} & Below secondary school & 83 & 8.7 \\
\hline & High school & 395 & 41.2 \\
\hline & Vocational school/College & 290 & 30.2 \\
\hline & University & 161 & 16.8 \\
\hline & Post-university & 30 & 3.1 \\
\hline \multirow{4}{*}{$\begin{array}{l}\text { Self-reported } \\
\text { health }\end{array}$} & Good & 95 & 9.9 \\
\hline & $\begin{array}{c}\text { Normal but there are some common } \\
\text { diseases of aging }\end{array}$ & 715 & 74.6 \\
\hline & Below average, chronic disease treatment & 110 & 11.5 \\
\hline & Poor & 39 & 4.1 \\
\hline
\end{tabular}


views of old people about death as well as their actions when facing death "that is approaching".

The demographic questionnaire included items pertaining to elderly age, gender, education level, profession, marital status, living arrangement, self-reported health and self-reported on satisfaction of material life.

The second part is designed into two scales: Senior citizens's view about death (17 items) and the elderly's action to death (19 items). The process of verifying and building these scales has been made in the investigation on the first participants test can be 292 Vietnamese elderly people, aging from 60 to 80 years-old, including 182 males (62.3\%) and 110 females (37.7\%). All the items whose loaded coefficient $<0.45$ were rejected (Burns \& Grove) [5]. We collected 12 items (loaded coefficient over 0.45 ) and 2 main factors after analyzing factors by varimax rotation method for the first scale "perceptions of the elderly about death". Based on items content, the factors were called by "belief of the elderly in the afterlife" and their "belief in causes of death of themselves". Similarly, for the second measurement scale, the result of factor analysis with varimax rotation also allowed us to obtain 13 items with two factors are "neutral acceptance of death" (the elderly focuses on doing things that they believe to be beneficial for current life before death) and "fear of death" (the elderly focuses on doing things that they believe to be beneficial for "second life" after death).

The factor rotation for both two scales allowed for the explanation above 50\% of the variance in the component solution. The Kaiser-Meyer-Olkin (KMO) of both scales is over 0.55, the Bartlett's result test is 0.000 and the Cronbach's alpha coefficient for these two scales is over 0.7. Alpha coefficient is also the same for each component of each scale. The values of Cronbach's alpha coefficient showed high reliability (internal consistency reliability) of each scale. So we decided to use this result for the official sample group of research.

To confirm the structure of the scales obtained above, we conducted a formal investigation on the 1000 participants who are Vietnamese elderly people, including 667 males (69.6\%) and 292 females (30.4\%). The analytical results confirmed the reliability of two scales obtained (alpha is over 0.7 for each scale also for its components). Loading factors are displayed in Table 2 and Table 3.

\subsection{Methodology}

\subsubsection{The Choice of the Method}

Research about the self-care behavior of people in general and elderly people in particular always make the researchers meet difficulties in the choice of research method suitable because of the diversity and complexity of the research problem. Therefore, we have decided to choose the cross-sectional study.

Quantitative research methods were used as the main methods of this research, allowing elucidating self-care behavior of the elders as well as their relationship with the independent variables such as age, gender, living situation, work and educational level. With a reliable material, this research method allows 
Table 2. Loaded factors after using varimax rotation method for the first scale.

\begin{tabular}{|c|c|c|c|}
\hline \multirow[b]{2}{*}{$\mathrm{N}^{0}$} & \multirow[b]{2}{*}{ Items } & \multicolumn{2}{|c|}{ Component } \\
\hline & & $\begin{array}{l}\text { Belief in } \\
\text { the } \\
\text { afterlife }\end{array}$ & $\begin{array}{l}\text { Belief in } \\
\text { causes of } \\
\text { death }\end{array}$ \\
\hline 1 & $\begin{array}{l}\text { Human have new lives after death and continue doing what } \\
\text { they do in the previous lives }\end{array}$ & 0.733 & \\
\hline 2 & Death is not the end. Dead body decays but soul remains & 0.692 & \\
\hline 3 & Dead relatives tempt elderly death & & 0.720 \\
\hline 4 & Everybody has his/ her destiny defined in previous life & 0.564 & \\
\hline 5 & $\begin{array}{l}\text { The elderly pass away due to sorrow, fear, tiredness brought } \\
\text { about by obsession over relatives' or spouse's death }\end{array}$ & & 0.644 \\
\hline 6 & Super natural forces take life away from the elderly & & 0.718 \\
\hline 7 & $\begin{array}{l}\text { The elderly pass away because they want to be tolerated by } \\
\text { Buddha and leave all the pain and sorrow behind }\end{array}$ & & 0.676 \\
\hline 8 & The elderly dies of sorrow and pain & & 0.600 \\
\hline 9 & Heaven takes lives away from the elderly & & 0.746 \\
\hline 10 & $\begin{array}{l}\text { Life after death takes place in heaven or hell depending on } \\
\text { whether a person is good or evil while hel she still lives, and } \\
\text { whether his/ her karma can be forgiven }\end{array}$ & 0.850 & \\
\hline 11 & Both worlds exist for the living and the dead & 0.754 & \\
\hline 12 & Life after death is just a faith & -0.522 & \\
\hline
\end{tabular}

Extraction method: Principal component analysis. Rotation method: Varimax with Kaiser normalization. a. Rotation converged in 3 iterations.

to apply on a large number of populations and to calculate the possible influences between the variables. To guarantee the objectivity of the quantitative research result, to meet the scientific credibility, 959 elders are selected randomly, which is made by obtaining the list of local elders provided by the local Association of the Elderly. Based on the list, we balance the ratio of elders selected in each district/ward/village of each province/city to ensure there representativeness for all objects in each province/city surveyed.

Based on the quantitative research results, we selected representative objects for each quantitative research result to conduct further interview to clarify this quantitative research result.

In other words, this study also used qualitative research methods to complete the lacuna of quantitative research methods, making the research results more reliable. Specifically, for each result relating to Vietnamese elders' belief in life after death (see Figure 1), the cause of their own death as well as their actions to prepare for it (see Figure 2), we select the most representative objects of each obtained result for deep interview. Accordingly the total deep interviews are 48 elders living in 6 provinces/cities within the survey scope. $2 / 3$ of interviewees are male, and the rests are woman; $41.67 \%$ is above 75 years old, $58.33 \%$ is within 60 75 years old; the educational level of $16.67 \%$ is post-university, $52.08 \%$ is high 
Table 3. Loaded factors after using varimax rotation method for the second scale.

\begin{tabular}{|c|c|c|c|}
\hline \multirow[b]{2}{*}{$\mathrm{N}^{0}$} & \multirow[b]{2}{*}{ Items } & \multicolumn{2}{|c|}{ Component } \\
\hline & & $\begin{array}{l}\text { Neutral } \\
\text { acceptance }\end{array}$ & $\begin{array}{c}\text { Fear of } \\
\text { death }\end{array}$ \\
\hline 1 & $\begin{array}{l}\text { I think that anyone is going to die someday so I always try to do } \\
\text { everything as much as I can to make myself happy and healthy }\end{array}$ & 0.648 & \\
\hline 2 & $\begin{array}{l}\text { When die I will be away from loved ones, the body will } \\
\text { be destroyed, so I am afraid of it. }\end{array}$ & & 0.514 \\
\hline 3 & $\begin{array}{l}\text { I don't want to die but I am not afraid of death, this law should be } \\
\text { considered as peace, we should live calmly the rest of the days. }\end{array}$ & 0.670 & \\
\hline 4 & $\begin{array}{l}\text { I usually do not talk about death because I am afraid that it } \\
\text { would come true if I talk about it repeatedly. }\end{array}$ & & 0.583 \\
\hline 5 & $\begin{array}{l}\text { I have lived a full life and I haven't felt ashamed with my family and } \\
\text { everyone around me so I face death happily without any regret. }\end{array}$ & 0.764 & \\
\hline 6 & $\begin{array}{c}\text { Death is inevitable, so I have specific plans to carry out when I alive } \\
\text { such as taking care of my descendants, completing unfinished things, } \\
\text { making a will, taking portrait... }\end{array}$ & 0.761 & \\
\hline 7 & $\begin{array}{l}\text { I am not willing to bring my life to an end in the late old-age } \\
\text { although I feel helpless and I feel like I am a trouble and a } \\
\text { burden to my children and my family. }\end{array}$ & & 0.532 \\
\hline 8 & $\begin{array}{l}\text { I always worship/incense carefully at home hoping for not being } \\
\text { ashamed with my ancestors prior to death. }\end{array}$ & & 0.544 \\
\hline 9 & $\begin{array}{l}\text { I always eat vegetarian food and pray Buddha for peace in mind in } \\
\text { order to be enlightened by Buddhism, a begger at Buddha's house. }\end{array}$ & & 0.777 \\
\hline 10 & $\begin{array}{l}\text { I always live morally, doing the best things during my remaining } \\
\text { time to leave happiness and virtue to my children. }\end{array}$ & 0.740 & \\
\hline 11 & $\begin{array}{l}\text { I always do good things for charity, go to pagoda to hope } \\
\text { for not going to hell but to heaven after death. }\end{array}$ & & 0.846 \\
\hline 12 & $\begin{array}{l}\text { I was not used to pray to Buddha, go to church/pagoda but when } \\
\text { I get old, I do it more often at home to make my mind peaceful, } \\
\text { hope to reduce my guilty prior to death. }\end{array}$ & & 0.799 \\
\hline 13 & $\begin{array}{l}\text { Prior to death I always try to complete some unfinished works } \\
\text { because I know that someone will continue my work. }\end{array}$ & 0.698 & \\
\hline
\end{tabular}

Extraction method: Principal component analysis. Rotation method: Varimax with Kaiser normalization.

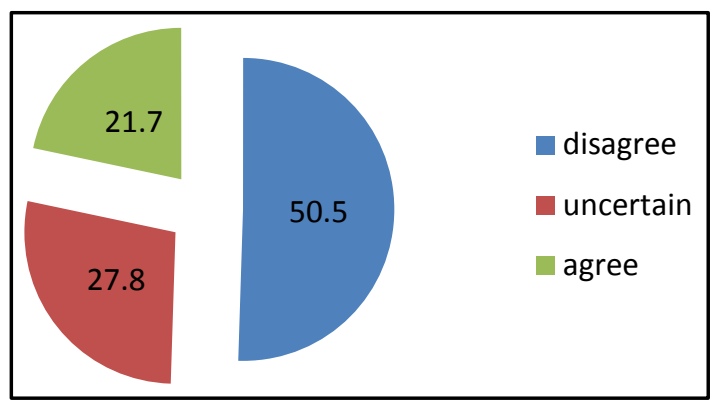

Figure 1. Belief of Vietnamese elderly in the afterlife.

school, $31.25 \%$ is vocational school/college; $62.5 \%$ of interviewees show that they are living with their life partner, the rest of $37.5 \%$ show that their life partners 


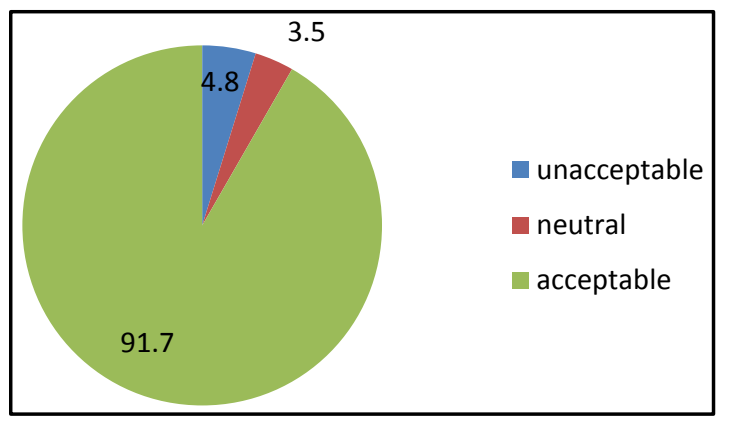

Figure 2. Actions reflecting to neutral acceptance of death of Vietnamese elderly.

have passed away.

\subsubsection{The Process}

All samples of the research are selected randomly with the support of the elderes' club in every provinces/cities and also the districts where the study to be investigated. The participants must meet the following criteria:

1) The person is over 60 years old

2) The person does not have a profound hearing problem

3) The person does not have a severe mental problem

The person volunteers to answer the questionnaire without incurring any strings attached. For those who may have difficulty in reading and writing, we help them to read each question and write down the answers directly to the questionnaire on their behalf. In other words, we are always available at the moment when the elders answer the questionnaire to assist them when needed. In the process of answering the questionnaire, if the person could find it difficult (tired, no time...) and do not want to continue to complete it, we respect their decision.

The confidentiality of the information obtained is guaranteed. The participation of the elder in the research is anonymous.

\subsubsection{Data Analysis}

Statistical calculations were performed using SPSS (Statistical Package for the Social Sciences) version 16.0. Specifically, we used the descriptive statistical analysis to calculate the average score, percentage data analysis as well as the statistical inference to understand the correlation, the nexus that may appear between the variables of the research. Factor analysis method and Cross-table analysis were also used as one of the main research method.

\section{Findings}

The findings from this study are presented below in three sections. The perception of the Vietnamese elderly about death is evaluated first. Following this, death attitudes are presented in the second section. The relation between regions of Vietnamese elderly and their death attitudes and perception about the death is 
the conclusion for this part 2 .

Finally, results from the influence of self-reported health, self-reported on satisfaction of material life and attitudes toward death and dying among Vietnamese elderly are discussed in the third section.

\subsection{Perception of Vietnamese Elderly about Death}

\subsubsection{Belief of Vietnamese Elderly in the Afterlife}

According to Mahendra and his colleagues [6], near-death studies as a legitimate field of inquiry was born in 1977 in Charlottesville (USA) and has now encircled the globe, inspiring researches, clinicians, scholars, educators, clerics, people from every walk of life in every discipline-not to mention the millions upon millions of experiences-newborns, babies, toddlers, children and teens of every age, adults and seniors of every race, job history, educational level, culture, philosophical bent, and financial advantage or disadvantage. Near-death experience having captured the world's attention, studies and research on the near-death phenomenon have directly impinged on what we think and know about the capacity of the human mind and spirit, our religion and social structures, and the prospect of life after death (Ring and Valarinon, 2006; Van Lommel, 2010). In other words, it seems that they have argued more and more, they tend to offer convincing evidence of existence of life after death. In Vietnam, although no epidemiological researches have been announced, but in the daily life, many people of Vietnam still believed that death is not the end. This might be the reason why Vietnamese people don't matter of what religion, Catholism, Budism, Caodaism or Hoahaoism etc., provided that they always worship their ancestors at home. They consider themselves as a bridge between their ancestors and their lives in the present and the future. They attentively take good care of the tombs, worship their death anniversaries and believe that the ancestors would watch over and bless them. Thus in any important event (new born baby, funeral, marriage, building house, career promotion...) Vietnamese people usually kowtow to report to their ancestors in order to expect further good things. The Vietnamese elderly assume that "death is not scary, instead it is to be united with the ancestors and their loved ones". So, they hope to see their ancestors after death, being go to Heaven/Nirvana in order to follow and bless the living. In fact, the old who have a chance approach death nearest, what did they think?

As presented in Table 2, 6 items were administered in this research to see if study participants believed in life after death. The results of our survey recorded something quite different from recorded sense of reality. Specifically, over a half of total objects have been asked for it the population did not believe in the existence of life after death. They came to a decision that "life after death is just belief", "only someone who is less knowledge still believe that they keep living somewhere after death". 27.8\% objects still "confused" about it. They "believe and doubt" because "there has not been scientific proof assert definitely for it". Just only $21.7 \%$ of the elderly believed that "death is not the end" and "people still have a new life after death" (see Figure 1). 
We believe that this is an interesting figure. It allows those who study to have a more accurate and objective look at the belief of the Vietnamese elderly in life after death. Another interesting fact is that the results of data processing allow us to note that $100 \%$ people believing in the afterlife also implement signifying acts which show neutral acceptance towards death. Accordingly, they focus on carrying out the work which is said to be meaningful for recent life before having to die. Probably because of the trusting in the afterlife that $76.4 \%$ of these people are not afraid of death: "being dead means going to heaven to see ancestors. So why have to be afraid?"; "I think death can come to anyone. Once god did not want us to live, then we don't need to hold on to life" ... The people showing this attitude are mostly at high school level (55.2\%) and intermediate - college (30.5\%). Definitely no elderly who has postgraduate qualification confirms that they believe in the second life. The people at this level mostly say that they are "confused" (55.3\%) or did not believe in this "fantasy" life (44.7\%). The result of Chi-square between knowledge and the belief in the existence of the second life after death has affirmed this result $\left(X_{(8)}^{2}=77.657, p<0.001\right)$, Cramer's V $=0.2$. In other words, knowledge did dominate a part of the elderly mind about death. Accordingly, it would be difficult to convince older people with higher education in Vietnam believing in the existence of a new life after death if it has not been proven by prestigious scientific research projects in the country and abroad.

So are there any differences between man and woman in showing their belief toward life after death? The result of T-test allows us to affirm the statistically significant difference between these two group of people $(t(957)=4.496, p<$ $0.001)$. In other words, older woman tend to believe in afterlife more than older man do. This was reflected through the previous studies in the field of elderly psychology (Berman \& Hays, [7]; Klenow \& Bolin, [8]). Besides, collected data also shows that the Vietnamese elderly belief in the after-life varies according to age $(F(2)=11.035, p<0.001)$. The below 75 elderly show their disbelief while the over 75 ones tend to believe. They believe that "man still have after-life and continues to do what they have been doing while living". For this belief, many, being asked in further interviews, show their calm acceptance of death, they wish to be interred/buried according to local ritual after death. They totally oppose cremation as they assume that "it is painfup", "dying without a full body" and it could not help them to "reincarnate as human". This result is completely compatible with what Keller et al. [9] has showed. Accordingly, the oldest group had greater belief in the afterlife than the middle-aged.

\subsubsection{Belief of Vietnamese Elderly in the Causes of Death of Themselves}

One of the sentences that many Vietnamese elderly usually say when they are about to die is: "Grandpa/grandma/dad/mom ... has come back to take me with them" or "God only allows us to live this far"... It seems that when close to death, Vietnamese elderly often "blame" objective reasons than subjective reasons. This is a reality that we would like to see through this study. Because up to now, there is some statistical analysis about the cause of death of the elderly 
(mainly focusing on the pathological causes or related to aging of the elderly), but the studies on subjective judgments of the elderly about their cause of death have not been done in Vietnam. Do Vietnamese elderly think that their death is caused by illness or due to a certain supernatural provisions? Or due to the invitation of the past relatives? The results of our study somewhat have initially answered these concerns. Specifically: Beside that most asked elderly (77.8\%) definitely did not believe that their death will be caused by supernatural provisions or by pains inside them, collected data allows us to affirm that $8.1 \%$ completely believe in these things, $14.1 \%$ of the people say they are "confused" at above arguments. The Chi-square results allow us to affirm a statistically significant connection between the elderly education levels and belief in supernatural powers (Buddha, God...) leading to their death $\left(X_{(8)}^{2}=75.43, p<0.001\right)$, Cramer's $\mathrm{V}=0.37$. Notably, none of those of below high school levels believe in that while $4.8 \%$ of those of from high school, college to post-graduate level agree with. They believe that the explanation of the elderly's death is that "the supernatural forces take them away". This belief is also influenced by their self judgment of health $\left(X_{(6)}^{2}=65.80, p<0.001\right)$, Cramer's $\mathrm{V}=0.25$. In other words, the majority of those believing that death are determined by the supernatural forces possessa "good" health or "some usual elderly diseases".

However, according to their statements, it seems that the elderly will be dead by "sorrow and pain" ( $M=1.71)$ or "because of the obsession with the death of loved ones" ( $M=1.51)$. This is affirmed by the Chi-square tests on the collected data. Accordingly marital status has a statistically significant connection with the Vietnamese elderly's expression of belief $\left(X_{(8)}^{2}=69.257, p<0.001\right)$, Cramer's V = 0.2 . More specifically, among those supporting that the elderly death is due to the obsession of the death of the loved ones, $70.6 \%$ are recognized to be living with their partners, the rest $29.4 \%$ shows that their partners have died. We believe that the results are consistent with what has been announced in the previous study. Because according to Adriaensen [10], in any places almost all the elderly always "remembered" about their past mates. They talked to themselves; they kept the most vivid memories about the deceased. Sometimes they talked to the deceased, by words, or by the thought in their minds. In particular, they often talked about the sense of loss in a permanent sentence: "if only our brotherlgrandpalgrandma is still alive". In other words, to elderly, the departure of their mates is a big shock which they have to face the rest of their lives. Even when facing the death of the partner, many act as if they were living: "my wife died recently and I always think that she still returns home. Thus in every meal, I set a bow and chopsticks in her place as usual and do not allow anyone to seat there". 3 years after the burying, they move the dead bonds to a new "house" in order to have a "tranquil residence" for them. According to Villeneuve [11], when his mate passes away, the elderly also loses a part of himself. So that we can easily see those believing that their death will caused an obsession for the mate "departure", up to $86.4 \%$ elderly say that they are currently living with their partners. To them, it is "the happiness of old age" and they "are afraid that 
their partner will be gone" before them and they would be sad and lonely".

\subsection{Death Attitudes of Vietnamese Elderly}

According to Gendro [12] human attitude towards death is dominated by culture, real-life experience, health, environment, personality, age and socioeconomic conditions in all ages. When the aged entered the ultimate phase of life, they also act as varied as other groups. Of course, we need to recognize that the experience of death is often varied and richer in the second part of life: The old see a lot of people dying at the same age. They have lost husbands/wives, children... and because they experienced ups and downs, they have time to be prepared for it so that the elderly seems feeling less fear of death and accepting death easier than young people (Sebag-Lanoe, 1986; Druet, 1987). So how about the Vietnamese elderly? How do they act prior to death when it is coming closer?

\subsubsection{Neutral Acceptance Attitudes in Front of Death}

The result at Figure 2 illustrated that the most of Vietnamese old decided to hold neutral acceptance attitudes in front of death (accounted for 91.7\%). As a result, they always tried to do the most meaningful things for the current life at the end of their life: "I thought that death is inevitable thing, so I make an attempt to do anything as much as I can for my health and happy family"; "I concentrated on caring for offspring, accomplishing unfinished piece of work, make a will... something I supposed that had better finish before death, so I feel secure" ... Besides, the figure showed that a very small part of senior citizens asked (accounted for 3.5\%) announced that they did not prepare to accept death. This group is essentially at aged $60-64(54.3 \%)$ and $65-75$ (45.7\%). No one at aged over 75 considered they are not ready to cope with this. Is age linked to attitudes and to behavior of the elderly in front of death? The outcome of Chi-square allowed us to come to a conclusion for this $\left(X_{(4)}^{2}=44.935, p<0.001\right)$. In other words, it seems that in our study, the more senior citizens aged are, the more they think about death and acceptit easier than younger people. This is completely similar to what Noel (1985), Mishara and Riedel (1984) (cite by Gendron, op.cit) pointed out in their research works. Accordingly, there is an increasing of death acceptance related to a gradual growth in age and the Vietnamese elderly are not an exception.

Concerning the respondents gender, there was not differently statistical significance between men and women from achieved figures on performing actions to ready to die $(t(945)=0.587, p>0.05)$. It is totally compatible with what Fortner and Niemeyer (1999) pointed out in their research for the old group nursing at home vs. living alone outside. Thus, the gender of elderly seems to be not affected the actions that express neutral attitudes of acceptance.

The marital status is recognized to have no statistically significant connection with the neutral acceptance in front of death of the Vietnamese elderly $\left(X_{(8)}^{2}=\right.$ $11.034, p>0.05$ ). Thus living with or without others (partner, descendants) ob- 
viously has no impact on the elderly attitude towards death, this attitude is rather to be examined in the connection with plenty other aspects. For examples, the data allows us to recognize that those most willing to accept death are those of the highest education level $\left(X_{(8)}^{2}=87.42, p<0.001\right)$ in our studied objects, Cramer's $\mathrm{V}=0.3$; or among the self-employed, $96.8 \%$ of manual workers show their willingness while only $87.2 \%$ of intelligent workers do so. Is it true that the more skillful and intelligent an elderly is, the more clearly he understands the meaning of living time, the more he wants to complete what is being done and thus is busier thinking of his than thinking of death?

\subsubsection{Fear of Death}

According to Thomas (1994, cited according to [12]), in a study is carried out in the UK, no one elderly fears for death when he was asked. In contrast, they labeled a positive value, admitting it as an inevitable part of their life. This is only partially reflected in our research work. As a result, $47 \%$ said that they are not afraid of death. $35.9 \%$ hesitated about it and $17.1 \%$ of respondents confirm that they felt a terrifying fear for death. They have accumulative terror over many things about death such as "when being dead, their body will decay", "death would tear them apart from their families"; they are afraid of talking about death because they believe "death will become real if it is mentioned frequently". This group of people also tremble at the thought that they will not go to heaven afterlife. Therefore, they would put a lot of effort into doing charity, visiting pagodas, praying to Buddha hoping all their sins would be diminished before they leave the real life.

We realize that age has a meaningful statistical link to behaviors which indicates the fear of death in the Vietnamese elderly $\left(X_{(4)}^{2}=34.622, p<0.001\right)$. Specifically in our study, it looks like the older the respondents are, the less indication of fear they express compared to their younger counterparts. The percentage of people who confirm their fear for death decreases alongside the age of respondents. Specifically, whereas $55.7 \%$ of the respondents in the age between 60 - 64 affirm their fear for death, only $37.1 \%$ of respondents in the age between $65-67$ show the same concerns. And 7.2\% of the respondents that are over 75 present this kind of fear. Although our study mainly focus on elderly respondents without any comparisons or references to perceptions/behaviors of younger counterparts toward death, we assume that it still reflects common trends which were already presented in previous researches. To put it simply, the elderly getting older do not care much about death.

As for the relationship between gender and behaviors indicating fear of death, we found out this was still a controversial matter. Whereas some previous studies demonstrated that male elder generally were more afraid of death than female elder (Léonard et al. 1986, cited according to [13]), other studies disagreed and proved otherwise (Neimeyer and Fortner, 1995, cited according to [4]). In this study, findings show that there is no difference between elder male and female respondents in term of behavior indicating fear for death $(t(953)=$ 
$1.545, p>0.05)$. These findings match with results that were shown by Kim's study (2008), which concentrated on the American Korean elderly. Similarly, the studies of Wu, Tang and Kwok [14], which targeted the Chinese elderly in Hong Kong, shared the same results. In accordance with these results, all of the studies mentioned above prove that gender does not affect fear of death. Being male or female does not increase or decrease one's fear of death. In other words, we have the subjective feelings that in Europe, gender decides how different an European elder exhibits his/her fear of death; whereas in Asia, there are no differences between elderly men and womenin behavior indicating fear of death. Is it one thing that distinguishes the Asian elderly and their European peers? This might be just a preliminary presumption. Further comparisons and intercultural studies are required for a firm assertion.

Shortly speaking, we realise that the older the Vietmamese people get, the more willing to accept death they are. Therefore they present less fear toward death. Gender influence their belief in the existence of life after death yet it seems not to be the factor forming the differences in the attitude toward death as well as the fear of death of Vietnamese elderly.

\subsubsection{Death Attitudes and Perception about the Death in Terme of Regions}

The one-way Analysis of Variance (ANOVA) allows us to notice the statistical difference of the death attitudes and perception about the death of the elders in 3 parts of the country in general as well as in 6 provinces/cities in particular. Specifically, the data allow us to assure that elders in the Center tend to believe in life after death more than those in the North and the South $(F(2)=77.281 ; p<$ $0.001)$. That might be the reason for that they show the least actions reflecting fear of death $(\mathrm{F}(2)=30.362 ; p<0.001)$. We believe that this is an interesting result for which the answer can be found in the regional historical features of Vietnam. In the history of Vietnam, during the war against France and the war against America, the Center (notably Nghe An, Ha Tinh, Quang Binh, Quang Tri province) suffered the most severe destructions which were experienced by most of the elder here. Thus they consider death "as light as down". They have no fear of death. However they do not show as much actions reflecting neutral acceptance as the elders in the North and the South. Is there any conflict in this research result? We believe that it can be explained. Although not being afraid of death, the elders in the Center is living with a great anxiety that the bodies of plenty of their dead relatives/acquaintances have not been found for proper bury. Thus the elders keep waiting and searching with a little hope that before dying they will be found. As no clues are found, they come to "spirit evoking" with the belief that the death's spirit could tell them the location of their corps. This contributes to the formation of the elders' firm belief in the life after death in this region.

In contrast, the elders in the North and the South don't seem not to believe in this second life. The historical factor mentioned above can partially explain it. 
Besides, in terms of society structure Hanoi and Ho Chi Minh city gather the most of intellectual elders.

As we have mentioned, the more intellectual they are the less they believe in life after death. They believe that "death is the end", "beyond remedy". Thus they try to make the best out of life in order not to be regretful for anything. In other words, they show the neutral acceptance of death $(\mathrm{F}(2)=27.492 ; p<$ $0.001)$.

\subsection{Self-Reported Health, Self-Reported on Satisfaction of Material Life and Death Attitudes for Vietnamese Elderly}

In 1996 National Interview Survey of Americawas reported that elders who self-esteem themselves as being in good and very good physical condition had a negative correlation with risk of mortality (Beisgen) [15]. According to Kim's statistical data (op.cit), elders with health problems have a high tendency to overly worry about death. In this research, all the accumulated data allow us to conclude that self-reported health of the elderly has a meaningful statistical link to their behavior indicating fear of death and tendency to accept death. Specific data are presented in Table 4.

Looking at Table 4, we can easily see that elders who think they are in poor state of health have neutral acceptance for death; they, however at the same time indicate the highest level of concern toward death. Is there any contradiction in this result? We think the result is explainable in term of psychology. Once elders have feelings that their health is diminishing, they know for sure they are getting closer to the last boundary. Thus, these people normally attempt to fulfill incomplete business and do meaningful things for descendants before they are gone for eternity. Still, death draws near make these elders the most vunerable

Table 4. Self-reported health and death attitudes in the Vietnamese elderly.

\begin{tabular}{|c|c|c|c|}
\hline \multicolumn{2}{|c|}{ Self-reported health } & \multirow{2}{*}{$\begin{array}{c}\text { Neutral acceptance } \\
2.62\end{array}$} & \multirow{2}{*}{$\begin{array}{c}\text { Fair of death } \\
2.02\end{array}$} \\
\hline \multirow{3}{*}{ Good } & Mean & & \\
\hline & $\mathrm{N}$ & 95 & 95 \\
\hline & Std. Deviation & 0.75 & 0.77 \\
\hline \multirow{3}{*}{$\begin{array}{l}\text { Normal but there are some } \\
\text { common diseases of aging }\end{array}$} & Mean & 2.92 & 1.57 \\
\hline & $\mathrm{N}$ & 703 & 711 \\
\hline & Std. Deviation & 0.35 & 0.68 \\
\hline \multirow{3}{*}{$\begin{array}{l}\text { Below average, chronic } \\
\text { disease treatment }\end{array}$} & Mean & 2.69 & 1.96 \\
\hline & $\mathrm{N}$ & 110 & 110 \\
\hline & Std. Deviation & 0.69 & 0.83 \\
\hline \multirow{3}{*}{ Poor } & Mean & 3.00 & 2.56 \\
\hline & $\mathrm{N}$ & 39 & 39 \\
\hline & Std. Deviation & 0.00 & 0.68 \\
\hline $\mathrm{F}$ & & $19.66^{*}$ & $39.08^{\star}$ \\
\hline
\end{tabular}

${ }^{\star} p<0.001$ 
ones to anxiety. They are scared of "something ambiguous", "afraid of separation from loved ones". This state of having mixed feelings about death seems to be a great nuisance to the elderly, hence, they should be provided thoroughly with more psychological support than anyone else in order to cope with death in the most relaxing manner.

According to Neimeyer and Van Brunt (1995, cited according to [4]), many studies in the field of elder psychology showed that elders' worries over death had negative correlation with their lives' satisfaction. To put it differently, the more the elderly satisfy with their lives, the less they worry about death. Our collected data presented in Table 5 partly reflect this judgment.

It seems like satisfaction of the elderly with their material lives does not have any impact on their behavior indicating neutral acceptance for death $(F=2.89$, $p>0.05)$. On the contrary, satisfaction, however, does significantly affect elders' fear of death. Elders who are not satisfied with their material lives tend to be more afraid of death than the other two groups of respondents. Was Erickson's right about his judgment? Is it true that elderly who are unsatisfied with their lives because they have not yet achieved perfect ego integrity? And therefore, they fear that death would prevent them from realizing their desire?

\section{Discussions}

Our research aims to understand the death attitudes and the perception about death of Vietnamese elderly living at home as well as some factors related to these questions. We have tried to collect data from the different religion of the country in order to obtain the most objective and reliable data. We found that the results reflect the actual diversity, rich in death attitudes and death perception of Vietnamese elderly at the present. There are some reasons why these findings are noteworthy. First, study on death in Vietnam is still very new and not really attract the attention of researchers in general as well as psychologist in

Table 5. Self-reported on satisfaction of material life and death attitudes of Vietnamese elderly.

\begin{tabular}{|c|c|c|c|}
\hline \multicolumn{2}{|c|}{ Satisfaction of material life } & \multirow{2}{*}{$\begin{array}{c}\text { Neutral acceptance } \\
2.85\end{array}$} & \multirow{2}{*}{$\begin{array}{c}\text { Fair of death } \\
2.22\end{array}$} \\
\hline & Mean & & \\
\hline \multirow[t]{3}{*}{ Unsatisfaction } & $\mathrm{N}$ & 68 & 68 \\
\hline & Std. Deviation & 0.53 & 0.59 \\
\hline & Mean & 2.88 & 1.61 \\
\hline \multirow[t]{3}{*}{ Satisfaction } & $\mathrm{N}$ & 765 & 773 \\
\hline & Std. Deviation & 0.42 & 0.73 \\
\hline & Mean & 2.77 & 1.98 \\
\hline \multirow[t]{3}{*}{ Very satisfaction } & $\mathrm{N}$ & 114 & 114 \\
\hline & Std. Deviation & 0.64 & 0.74 \\
\hline & $\mathrm{F}$ & $2.89^{\star}$ & $31.68^{\star *}$ \\
\hline
\end{tabular}

${ }^{\star} p>0.05 ;{ }^{* *} p<0.001$. 
particular. Meanwhile, Vietnamese population is obviously growing old. The number of the Vietnamese elderly is increasing as a result, yet, understandings of elderly psychology are something that our society lacks. Hence, preparation for the old lives is met by many limitations. In that circumstance, our team is looking forward to further, deeper studies on how the elderly perceive death and other factors relevant to the issue. Second, the findings in the present study suggest that in addition to studying well-being, researchers should pay far more attention to the potentially important role that religious beliefs may play in the restoration and maintenance of physical health and also of well-being.

In the process of devising plans for further research, it is important to keep the limitations of our study in mind. Two shortcomings are discussed briefly below.

The first limitation in our work has to do with the measurement developed by ourselves.

Although researching tools in this study is designed based on preceding pieces of research as well as typical characteristics of Vietnamese culture-religion, we realize that our statistical data gathered by the tools have not fully reflected the abundance and variety of the Vietnamese elderly spiritual life when they discuss of death. Therefore, a deeper, more extensive researching tool is required to unveil their attitude as well as their perceptions toward death for further research in Vietnam.

Second, our measures of satisfaction of material life and health status are based on respondent self-reports. This raises obvious questions regarding self-report bias. Although we presented data earlier that suggest that self-reports may be reliable, researchers would benefit from using other ways to assess these dimensions, including income, current living standard, the recent medical certificate of the elderly... during the interview.

\section{Conclusion}

In conclusion, our result has demonstrated that the death attitudes and perception about the death of the Vietnamese elderly has similarities with previously published research but it is also associated with the socio-cultural-historical aspects of Vietnam. It is hoped that this study takes another step towards understanding an ever popular topic area that has relevance to a growing number of Vietnamese elderly.

\section{Acknowledgements}

This research received funding from the Vietnam National University (VNU-Hanoi) (Grant number: QG.16.45).

\section{References}

[1] Kastenbaum, R. (2006) The Psychology of Death. 3rd Edition, Springer Publishing Company, Inc. 
[2] Bryant, C.D. and Peck, D.L. (2009) Encyclopedia of Death and the Human Experience. Sage publications, Inc. https://doi.org/10.4135/9781412972031

[3] Tomer, A. (2000) Death Attitudes and the Older Adult. Theories, Concepts and Applications. Edwards Brothers, Ann Arbor.

[4] Kim, H.H. (2008) Impact of Spirituality and Religion on Attitudes toward Death and Dying Among Korean Seniors Living in Chicago. Dissertation/Thesis, Loyola University Chicago.

[5] Burns, N. and Grove, S. (2005) The Practice of Nursing Research: Conduct, Critique, and Utilization. 5th Edition, Elsevier Saunders, St. Louis.

[6] Mahendra, P., Jagadheesan, K. and Peake, A. (2012) Making Sense of Near-Death Experiences: A Handbook for Clinicians. Jessica Kingsley Publishers.

[7] Berman, A. and Hays, J.E. (1975) Relation between Death Anxiety, Belief in Afterlife, and Locus of Control. Journal of Consulting and Clinical Psychology, 41, 318-321. https://doi.org/10.1037/h0035122

[8] Klenow, D.J. and Bolin, R.C. (1989) Belief in an Afterlife: A National Survey. Omega, 20, 63-74.

[9] Keller, J.W., Sherry, D. and Piotrowski, C. (1984) Perspective on Death: A Developmental Study. The Journal of Psychology, 116, 137-142. https://doi.org/10.1080/00223980.1984.9923628

[10] Adriaensen, M.C. (2009) La personne âgée face au deuil: Comment lui venir en aide? [The Elderly Person Facing Bereavement: How to Come Help Them?]. 1st Edition, De Boeck Supérieur.

[11] Villeneuve, C. (2006) L'intervention en santé mentale: Le pouvoir thérapeutique de la famille. [Intervention in Mental Health: The Power of the Therapeutic Family]. Les Presses de l'Université de Montréal.

[12] Gendron, C. and Carrier, M. (1997) La mort, condition de la vie. [Death, Condition of Life]. Presses de l'Université du Québec.

[13] Fortner, B.V. and Neimeyer, R.A. (1999) Death Anxiety in Older Adults: A Quantitative Review. Death Studies, 23, 387-411. https://doi.org/10.1080/074811899200920

[14] Wu, A.M.S., Tang, C.S.K. and Kwok, T.C.Y. (2002) Death Anxiety among Chinese Elderly People in Hong Kong. Journal of Aging and Health, 14, 42-56. https://doi.org/10.1177/089826430201400103

[15] Beisgen, B. and Kraitchman, M.C. (2003) Senior Centers: Opportunities for Successful Aging. Springer Publishing Company, Inc. 